\title{
Continuidades e descontinuidades: a arqueologia Aratu-Sapucaí e a história indígena Cayapó
}

\author{
Gabriel Zissi Peres Asnis* \\ Marcel Mano**
}

ASNIS, G.Z.P.; MANO, M. Continuidades e descontinuidades: a arqueologia Aratu-Sapucai e a história indígena Cayapó. R. Museu Arq. Etn. 34: 154-173, 2020.

Resumo: $\mathrm{O}$ artigo busca problematizar as associações diretas e acríticas entre grupos ceramistas da tradição arqueológica Aratu-Sapucaí e grupos conhecidos na documentação como Cayapó. Nas regiões dos atuais Triângulo Mineiro, Alto Paranaíba, sul de Goiás e norte de São Paulo, a sobreposição espaço-temporal de ocupações de grupos daquela tradição e os mencionados nas fontes fez propor-se uma continuidade cultural entre povos afastados historicamente. A imagem de uma história linear e de uma cultura fossilizada esqueceu-se que os indígenas das fontes documentais foram descritos em situação colonial, um ambiente marcado por intensos contatos e disputas de interesses. De fato, tanto dados arqueológicos como documentais insistem em mostrar constantes contatos e transformações. Registros fósseis dessa tradição apontam influências de outras; e registros documentais dos Cayapós evidenciam uma complexa e intricada rede de relações com diferentes alteridades. Por isso, tanto a história dos grupos produtores da cerâmica AratuSapucaí quanto a dos Cayapós coloniais não podem ser pensadas como isoladas, mas sim como compostas de fronteiras porosas nas quais se expandiram, se retraíram e se sobrepuseram diversos agenciamentos. Nessas fronteiras moldadas pelos contatos, transitaram em redes não estruturadas pessoas, bens simbólicos, materiais, conhecimentos e técnicas que, por todos os lados e em todas as direções, direta ou indiretamente, impactaram e renovaram tradições. Sob essas condições, artefatos arqueológicos devem ser o registro físico dessas mudanças, e não a evidência de uma continuidade. O artigo mobiliza então dados da Arqueologia, da História Indígena e da Antropologia com o propósito de levantar barreiras no trajeto que leva grupos do passado pré-colonial a aterrissarem no contexto colonial, ou vice-versa.

Palavras-chave: Aratu-Sapucaí; Cayapó; Mossâmedes; Tradições arqueológicas; História dos contatos.

\footnotetext{
* Mestre em Ciências Sociais pelo Programa de Pós-Graduação em Ciências Sociais da Universidade Federal de Uberlândia (UFU). Graduado em História pela mesma instituição. Membro do Grupo de Estudos em Arqueologia, Etnologia e História Indígena (Gepaehi/UFU).gabrielasnis@gmail.com

" Doutor em Antropologia. Professor Associado do Programa de Pós-Graduação em Ciências Sociais e do Programa de Pós-Graduação em História da Universidade Federal de Uberlândia (ỦFU). Coordenador do Grupo de Estudos em Arqueologia, Etnologia e História Indígena (Gepaehi/UFU).marcelmano@ufu,br
}

\section{Introdução}

ofício consagrado na Arqueologia é
o de compilar, comparar e classificar vestígios com o objetivo de identificar povos e definir fronteiras. Por meio das semelhanças técnicas e estéticas dos artefatos e/ou de sua distribuição espacial em ambientes similares, 
ela encontrou guias fósseis e criou tradições. Com base nelas, parte dessa Arqueologia apressadamente associou os vestígios do passado arqueológico com os grupos indígenas mencionados nas fontes documentais.

Há nesse último passo, porém, ao menos dois problemas entrelaçados: de ordens da História e da Antropologia. O primeiro pressupõe a continuidade histórica entre povos afastados temporalmente; em consequência, o segundo pressupõe a cultura como isolada e como essência fossilizada.

Mais recentemente, pesquisas arqueológicas e etnológicas de cunho etnoarqueológico têm problematizado o assunto. As críticas aos modelos empregados para estabelecer relações entre artefatos materiais e culturas já abrangem uma gama de considerações. Vão desde as denúncias à atribuição de significados aos objetos e bens como prática discursiva do Estado e de movimentos nacionalistas (Jones 1997; Tomaso \& Lima Filho 2012), como relação de poder (Schiavetto 2005) e como colonialidade (Eremites de Oliveira 2016), até as atuais apropriações e interpretações indígenas (Eremites de Oliveira 2017; Silva 2002; Velden 2018). Neste último caso, não interessa mais a natureza técnica ou estética dos artefatos, tão cara àquela Arqueologia das tradições, mas as apropriações e interpretações cosmológicas e políticas que os indígenas produzem a respeito dos sítios e vestígios em seus territórios. Sejam como cacos de espíritos (Velden 2018) ou como restos das panelas dos heróis culturais (Silva 2002), potes são de pessoas, de demiurgos e de espíritos dos antepassados.

Apesar disso, de maneira quase naturalizada, parte da Arqueologia ainda insiste em associar tradições tecnológicas ceramistas pré-coloniais com povos e culturas. Na região dos atuais Triângulo Mineiro, Alto Paranaíba, sul de Goiás e norte de São Paulo, a distribuição e expansão da tradição Aratu-Sapucaí "representada pela presença de arestas de vasos geminados e cacos de possivivis igaçabas" (Fagundes 2015: 120) confeccionadas sem decoração, em estética escura e lisa, coincide com as informações documentais que a partir do XVIII mencionam a região como ocupada por grupos Cayapó. A tentação foi grande, e logo passou-se a propor uma linha de continuidade temporal e cultural entre a tradição Aratu-Sapucaí e os Cayapó da documentação.

No entanto, os Cayapó descritos a partir do encontro colonial não correspondem a uma realidade empírica incontestável, nem são a imagem primeva dos índios pré-coloniais. Como vários outros termos usados na documentação, Cayapó parece ter sido apropriado para uma construção colonial de etnicidades e de fronteiras étnicas e, por isso, um apelativo genérico que abrangia diferentes grupos. Além disso, diferentemente dos produtores de artefatos cerâmicos da tradição Aratu-Sapucaí, os grupos mencionados no século XVIII já se encontravam em situação colonial, um ambiente marcado por disputas de interesses, negociações e conflitos entre diferentes agentes históricos que colocaram esses grupos indígenas em contato com diferentes alteridades, com as quais estabeleceram uma rede trançada por diferentes estratégias.

Com base nessa história dos contatos o artigo quer problematizar a relação AratuSapucaí - Cayapó para a região mencionada. Para isso propõe escapar do espelho enganoso de uma relação homóloga entre etnia e artefato, cujo resultado foi atribuir artefatos a coletividades sem passar pelos indivíduos que os produziram, os usaram e os fizeram circular. Está claro que materiais, técnicas e estilos podem ser dados nas combinações de um número de possiblidades oferecidos pela tradição. Afinal, a oleira sempre tem a seu dispor um conjunto de técnicas e de materiais herdados; mas temos de considerar que o arsenal de possibilidades da tradição se reformula permanentemente por imitações, invenções, empréstimos, trocas, roubos, aquisições, apropriações e extorsões de elementos e saberes resultantes das redes de contatos. Quando traçada, essa história não pode ser a do espírito humano, nem a da etnia e da cultura tomada na eternidade, mas uma história política e cultural tortuosa que resultou em diferentes trajetos, rotas e itinerários traçados por esses grupos dos Cayapó coloniais. 


\section{A tradição Aratu-Sapucaí}

As tradições arqueológicas foram definidas no Brasil por meio dos trabalhos do Programa Nacional de Pesquisa Arqueológica (Pronapa). Coordenado por Betty Meggers e Clifford Evans da Fundação Smithsonian de Washington (Estados Unidos). A partir da década de 1960, o programa teve como objetivo reconhecer "guias" arqueológicos que deram origem às tradições e fases.

O casal de arqueólogos trouxe para o Brasil um método de interpretação para a análise dos materiais cerâmicos denominado Método Ford, que se baseava nas micro-diferenciações e nas análises quantitativas. Os principais discípulos de Meggers e Evans foram Ondemar Dias e Valentin Calderón, responsáveis por criarem a tradição Aratu-Sapucaí. O programa obteve patrocínio do Conselho Nacional de Desenvolvimento Científico e Tecnológico (CNPq) e da Smithsonian Institution e teve importante papel no desenvolvimento da Arqueologia enquanto ciência no Brasil. ${ }^{2}$

"Padronizar fenômenos arqueológicos sob um guarda-chuva conceitual em busca de estabelecer um quadro do desenvolvimento pré-histórico do Brasil, foi a grande ambição do Programa para a Arqueologia Brasileira" (Soares 2012: 23), sendo esse o seu próprio problema, pois padronizou, por meio de análises materiais, culturas inteiras. Pautou-se somente em dados quantitativos e desconsiderou o dinamismo das populações, os contatos entre os diferentes grupos e as mudanças ocorridas em seus universos de significação. Daí a necessidade de novos trabalhos levarem em consideração não as fases e tradições, mas os detalhes "descartados" pelo programa para propor outras interpretações dessas histórias indígenas.

Mesmo cientes dessas limitações, é necessário apresentar, de forma geral, a tradição Aratu-Sapucaí. Inicialmente, Aratu e Sapucaí

1 De 1965 a 1970.

2 As primeiras pesquisas arqueológicas realizadas no Brasil ocorreram na região de Lagoa Santa, em Minas Gerais, e foram desenvolvidas pelo norueguês Peter Lund, no século XIX. foram consideradas tradições diferentes, mas mais tarde reunidas em uma só. A Aratu foi definida por Valentin Calderón na Bahia, ${ }^{3}$ em 1969. Os materiais cerâmicos tomaram o nome do centro industrial no qual foram encontrados: o de Aratu. A tradição Sapucaí foi definida por Ondemar Dias Júnior em 1970/1971, em Minas Gerais, na bacia mineira do rio Paraná, nos vales do rio Grande e Verde (Prous 1992). A evidencia de uma homogeneidade estética entre as duas tradições levaram-nas a serem classificadas como uma única: a Aratu-Sapucaí. De acordo com os especialistas, a tradição Sapucaí é "ligada ao horizonte agrícola ao qual pertence também a tradição Aratu, da qual é difícil de separar" (Schmitz et al. 1982: 88).

Como um todo, a Aratu-Sapucaí representa grupos agricultores que teriam ocupado a região do litoral nordestino (Bahia, Sergipe, Alagoas, Ceará e Rio Grande do Norte), o Brasil Central (Mato Grosso e Goiás) ${ }^{4}$ e o Sudeste (Espírito Santo, Minas Gerais e São Paulo). Em pesquisa realizada por Soares (2013), os sítios Aratu-Sapucaí concentram-se nas áreas litorâneas, sobre a Planície Costeira e sobre o Planalto Central e Meridional, no interior do Brasil. Esses sítios caracterizam-se "por ter vasilhames predominantemente simples, produzidos com antiplástico mineral e formas esféricas e ovoides grandes" (Schmitz et al. 1982: 49). ${ }^{5}$ Tais vasilhames, de acordo com Rice (1987), possuíam múltiplos usos, como armazenamento de alimentos, líquidos e urnas funerárias, entre outros, "de modo que o contexto arqueológico é meramente seu lugar final, mais do que um indicador acurado de como foi sua vida útil" (Caldarelli 2003: 220).

3 As primeiras descobertas ocorreram nos sítios Guipe, Beliscão e Desidério.

4 Sendo em Goiás a fase Mossâmedes como representante da tradição Aratu-Sapucaí, que será retomada posteriormente.

5 O antiplástico é o elemento adicionado no preparo da cerâmica, podendo ser um mineral (areia) ou um vegetal (casca de árvore), oferecendo consistência ao vasilhame, principalmente no momento de secagem e da queima. 
[...] a tradição Aratu caracteriza-se pela presença de cerâmica não decorada, com antiplástico mineral, uso ocasional de inciso simples nas bordas, urnas funerárias piriformes, vasilhas globulares, hemisféricas, formas duplas e vasilhas com bordas ondulares. Não se registram pratos e nem assadores de mandioca. No que se refere à morfologia das aldeias, alguns sítios [...] possuiam formato circular, com fundos de cabana distribuidos ao redor de uma praça central. Quanto aos padrões funerários, urnas foram encontradas tanto enterradas sob o solo de habitação, quanto dispostos em grupos fora da área da aldeia (Caldarelli 2003: 221).

As características gerais que servem como "guias fósseis" do material cerâmico arqueológico encontrado nos sítios AratuSapucaí são vasilhas de formato cônico utilizadas para o armazenamento de comida e posteriormente como urnas funerárias. Também são encontradas as de formas globulares, semi-globulares e formas duplas (RobrahnGonzalez 2001). "As urnas seguem um padrão de formato piriforme com $75 \mathrm{~cm}$ de altura por $65 \mathrm{~cm}$ de largura máxima no bojo e com $45 \mathrm{~cm}$ de boca, não apresentam decoração e possuem uma tampa em formato de tigela invertida para fechar a abertura da boca" (Soares 2012: 25).

O modo de manufatura típica da tradição Aratu-Sapucaí é o acordelamento, no qual os roletes confeccionados são colocados uns sobre os outros até dar forma ao vasilhame. A base é constituída com uma massa de barro bem grossa que serve como sustentação à peça.

Ao discorrer sobre a cerâmica Aratu-Sapucaí encontrada em Minas Gerais, Prous (1992: 50) afirma que ela é:

caracterizada pela presença de vasos grandes com cacos muito espessos, incluindo urnas funerárias globulares e não piriformes com mais de um metro de diâmetro do bojo; ao lado desses recipientes enormes, aparecem vasos pequenos, de paredes finas e "bases perfuradas", ou seja, vestígios prováveis de "cuscuzeiros"; os cachimbos tubulares são encontrados com alguma frequência.
No que se refere à morfologia das aldeias, os sítios evidenciados nas pesquisas são circulares, ovais ou em ferradura, de $13.000 \mathrm{~m}^{2}$ a $345.000 \mathrm{~m}^{2}$ (Eremites de Oliveira \& Viana 2000), podendo ter de um a três anéis concêntricos de habitações ao redor de uma praça central, contando com um diâmetro de 100 a 560 metros (Caldarelli 2003) e que suportava de 11 a 90 casas. As aldeias menores possuíam capacidade para abrigar centenas de pessoas e as maiores chegavam a abrigar até 2.000 pessoas. A origem das aldeias estaria associada, segundo Wüst \& Barreto (1999), a "emergência local destas aldeias, como resultado de soluções frente a processos históricos, envolvendo pressões demográficas, interação com grupos vizinhos e necessidades defensivas, resultando numa estrutura organizacional e cosmológica única" (Caldarelli 2003: 222). Ao analisar os vestígios arqueológicos em relação a informações ambientais, Soares (2013) afirma que, em sua maioria, os sítios Aratu-Sapucaí estão localizados próximo a córregos de médio e pequeno porte, deixando de lado os grandes rios, em ambientes abertos e geralmente em mata em vez de cerrado.

Com relação às datações do material arqueológico evidenciado por Calderón, a ocupação Aratu na Bahia teve início no século IX, mais especificadamente o sítio Guipe datando de $870 \pm 90$ A.D; ${ }^{6}$ o sítio Beliscão, de $1360 \pm 40$ A.D; e o sítio Desidério, de $1050 \pm 250$ A.D. Entretanto, as datações mais antigas da tradição Aratu-Sapucaí estão nos sítios encontrados em Goiás, com datações de 810 A.D, 830 A.D, 860 A.D, 880 A.D, 970 A.D, 990 A.D e 1055 A.D, representados pela fase Mossâmedes.

Segundo as datações obtidas até o momento, o horizonte cronológico mais antigo da tradição situa-se no estado de Goiás.

É também no centro-sul deste estado, em meio à formação do Mato Grosso de Goiás, que a tradição apresenta seu momento de apogeu, figurando as grandes aldeias em formato anelar com alta densidade populacional e uma grande concentração espacial de sítios arqueológicos de menores dimensões (Soares 2013: 66).

$6 \quad \mathrm{AD}=$ Anno Domini (Ano do Senhor). 
Cronologicamente temos, em seguida, Bahia, Tocantins, Minas Gerais/São Paulo, Paraná e Espírito Santo, ${ }^{7}$ com ocupações menos densas e que são importantes para a análise a seguir sobre as possíveis origens dessa tradição.

Conforme Robrahn-Gonzalez (1996), os padrões observados na tradição Aratu se assemelham a certos contextos amazônicos, principalmente aos dos sítios localizados no Alto Madeira, em Rondônia, com datações do século VI a.C. Essa hipótese se vincula à ideia de que a tradição Aratu pertence ao tronco linguístico Macro-Jê (Brochado 1991), que teria se originado na Amazônia e depois se deslocado em direção ao Centro-Oeste. Além disso, as datações dos sítios Aratu mais antigos (primeiros séculos d.C.) já indicariam uma economia baseada na agricultura do milho e uma indústria cerâmica desenvolvida que, segundo Robrahn-Gonzalez (1996), fortaleceriam a hipótese de uma origem externa.

\section{Considerando esta possivel origem} amazônica, a referida autora conclui que tais incursões ao Centro-Oeste não teriam se dado por meio das grandes vias fluviais do Xingu e Tapajós, uma vez que a distribuição dos sítios supõe uma rota no sentido oeste-leste, do Amazonas/Rondônia, para o centro de Goiás, cruzando os rios Tapajós, Xingu e Araguaia (Caldarelli 2003: 221).

Dessa forma, ainda segundo RobrahnGonzalez (1996), o que explicaria a presença Aratu no Nordeste seria um desmembramento dos grupos que saíram da região amazônica no sentido oeste/leste e que teriam cruzado as redes fluviais de Tapajós, Xingu e Araguaia, dividindo-se em um grupo que seguiu em direção ao Nordeste e o outro em direção ao Sul, no sentido de Goiás, Minas Gerais e São Paulo. "Neste caso, os portadores desta tradição cerâmica teriam utilizado o vale do São Francisco como via de penetração em direção ao sudeste" (Caldarelli 2003: 222). Entretanto, a autora (Robrahn-Gonzalez 1996) afirma que houve

7 Por não se tratar do objetivo central deste artigo, as datações nesses outros estados não serão apresentadas. várias ondas migratórias, com diferentes formas de contato e pluralidade de processos no desenvolvimento cultural e que durante 700 anos intensificaram-se os assentamentos em Mato Grosso, Goiás e Tocantins, visto que "a região do vale do Paranaíba é tida como área 'core' do desenvolvimento desta tradição, formada por levas migratórias que estariam penetrando no território por volta do século VIII e IX, consolidando-se neste último" (Soares 2013: 64) durante o qual grandes aldeias foram originadas. ${ }^{8}$

Isso fez com que essa autora propusesse que a região de Goiás faria parte da zona central da tradição Aratu-Sapucaí, representada pela fase Mossâmedes, e que os demais estados (Bahia, Tocantins, Minas Gerais/São Paulo, Paraná e Espírito Santo) seriam zonas periféricas, por apresentarem datações mais recentes do que as de Goiás e possuírem densidades populacionais inferiores à das grandes aldeias do Centro-Oeste. É essa fase denominada Mossâmedes que logo cedo passa a ser identificada com grupos que as fontes coloniais denominavam de Cayapó.

\section{A fase Mossâmedes e os Cayapó meridionais}

Identificada por Pedro Ignácio Schmitz nas décadas de 1970 e 1980, durante o Programa Arqueológico de Goiás, Mossâmedes foi considerada uma fase da tradição Aratu-Sapucaí em uma reunião no ano de 1980 em Goiânia (a mesma que uniu as duas tradições em uma). Como descrito anteriormente, é nessa fase que estão os sítios mais antigos dessa tradição, ${ }^{9}$ o que permitiu deduzir que a região CentroOeste brasileira poderia ser a zona central de dispersão desses grupos.

Os sítios cerâmicos dessa fase localizamse em uma extensa área, principalmente a de Mato Grosso e Goiás, a do sudeste de Goiás, e a de Meia Ponte e Alto Araguaia Goiano,

8 Esse seria um dos motivos que levariam à associação entre a tradição Aratu-Sapucaí e os grupos históricos denominados Cayapó, como veremos.

9 A datação mais antiga está no sítio GO-CP-02: $1140 \pm 90$ A.P. (Antes do Presente, ou seja, antes de 1950) (Schmitz et al. 1982). 
correspondendo às serras do Caiapó, Dourada e dos Pirineus. Um dos municípios em que encontraram material cerâmico foi o de Mossâmedes, ${ }^{10}$ que deu nome à fase.

Esta área pertence a três bacias: a do Araguaia, através dos rios Claro, Almas e Caiapó; do Paranaíba, através dos rios Claro, Turvo, dos Bois, Meia Ponte e Corumbá; do Tocantins, através dos rios Uru/Almas e Sucuri. Ocupa mais densamente a parte alta desses cursos de água e os interflivios correspondentes. Nenhum dos sitios encontra-se na borda de nenhum rio, mas sobre córregos de águas perenes ou eventualmente ribeiras dos quais distam entre 70 e 500 m (Schmitz et al. 1982: 50).

As características da cerâmica se assemelham aos modelos gerais da tradição Aratu-Sapucaí, com grandes urnas piriformes e vasilhas em forma ovoide, elipsoide, esferoide e cilíndrica (ver Schmitz et al. 1982; Soares 2012). "Os sítios encontram-se sobre pequenas elevações e distam da água mais próxima de 70 a 700 metros. As áreas de deposição arqueológica variam de $120 \times 140 \mathrm{~m}$ a $360 \times 400$ m" (Soares 2012: 47). Além dessas características, "expõe traços que indicam a influência da Tradição Uru do Brasil Central, como a utilização do antiplástico vegetal (cariapé), bases planas de $90^{\circ}$ e grandes pratos possivelmente utilizados no preparo da mandioca" (Rasteiro 2016: 97), atestando as relações de contato entre diferentes tradições, tema ao qual se voltará.

A morfologia e a localização das grandes aldeias circulares da tradição Aratu-Sapucaí foram associadas às dos Jê, entre eles, os Kayapón ${ }^{11}$ (Prous 1992). Com base na localização dos

10 O nome da cidade advém do aldeamento colonial de São José de Mossâmedes, construído em 1775 pelo governador da capitania de Goiás, José de Almeida e Vasconcelos, o barão de Mossâmedes, por meio das exigências instituídas pelo Diretório Pombalino. Para mais informações ver Asnis (2019).

11 Ao longo do artigo este termo aparecerá com a letra C (Cayapó), como também com a letra K (Kayapó). O primeiro é o seu modo de aparecimento na documentação histórica e o segundo é a normatização da Associação Brasileira de Antropologia (ABA), sendo o modo de aparecimento na Etnografia. sítios arqueológicos da fase Mossâmedes e nas informações contidas nos mapas etno-linguístico de Loukotka e etno-histórico de Nimuendajú (2002), Schmitz et al. (1982: 266) e Ataídes (1998) foram os primeiros a levantarem a hipótese da relação entre tradição Aratu-Sapucaí e Cayapó meridionais, depois retomada para os fusos perfurados encontrados em sítios do Triângulo Mineiro que "sugerem, por comparação etnográfica com os Kaiapó Setentrionais, fiação e tecelagem" (Alves 1992: 37). O ponto chave aqui é justamente o da relação entre a tradição Aratu-Sapucaí mais especificadamente a fase Mossâmedes e os grupos Cayapó meridionais descritos na documentação histórica a partir do século XVIII.

Tanto a localização proveniente do primeiro registro histórico feito sobre os Cayapó, pelo sertanista Antônio Pires de Campos em 1723 (na atual divisa do Triângulo Mineiro e o estado de Goiás), quanto as descrições feitas anteriormente sobre a localização dos achados arqueológicos da fase Mossâmedes parecem confirmar determinada correspondência entre a zona ocupada no período pré-colonial pela tradição Aratu-Sapucaí e no período histórico pelos Cayapó, além do padrão das aldeias.

\section{Tanto a coincidência positiva, da presença} dos sítios da fase Mossâmedes na área atribuida etno-historicamente aos Kayapó do Sul, como a negativa, da ausência de sítios desta fase em áreas para as quais não há notícias desta tribo, nos leva à suposição, até qualquer comprovação em contrário, de que os Kayapó do Sul podem ser descendentes dos que nós arqueologicamente, identificamos como fase Mossâmedes (Schmitz et al. 1982: 266).

O grande problema é que a contiguidade espacial, estabelecida como prova da continuidade histórica entre uma tradição pré-colonial com um grupo colonial, deixa lacunas. Ela esquece que o espaço é uma constante construção humana e histórica, mutável e não perene, constantemente transformado pelas relações que os seres humanos estabelecem entre si, com a natureza e com os outros povos; por isso são resultado do acúmulo de invenções, de trocas, de guerras, de negociações e agenciamentos que construíram a tradição de um povo. Atestar somente por fatores espaciais 
e materiais que uma sociedade continuou sendo a mesma desde o século IX d.C. é negligenciar fatores de mudanças advindos, por exemplo, dos processos históricos de contatos desses grupos a partir do século XVIII. e descartar a presença de características e influências de outras tradições e grupos no material Aratu-Sapucaí. Com base nisso, passam a ser questionadas as correlações simplistas que até então haviam sido estabelecidas entre as fases cerâmicas, os grupos descritos nas fontes coloniais e os povos indígenas descritos pela etnologia.

\section{[...] a tradição Aratu foi correlacionada} aos grupos Kayapó, sem a demonstração de uma continuidade entre o registro arqueológico e o presente etnográfico (Schmitz et al, 1982). Os trabalhos de Wüst (1983; 1990; 2000) e González (1996) foram particularmente úteis nesse sentido, além de terem contribuido para um melhor entendimento da dinâmica cultural, envolvendo processos de continuidade, ruptura e interação cultural (Caldarelli 2003: 221).

Isso se deu porque o próprio material arqueológico não é simplista, pois apresenta muito mais do que características fixas e gerais. "A cerâmica não necessariamente caracteriza a etnia" (Soares 2012: 22). Há especificidades nela que demonstram uma complexa relação entre diversos grupos antes mesmo da chegada dos não índios, e mesmo as "semelhanças na cultura material podem mascarar complexos fenômenos de redes de trocas" (Wüst \& Carvalho 1996: 48). Além disso, os próprios grupos coloniais retratados nos documentos históricos não são grupos fechados ou estagnados no tempo. Houve transformações e rupturas, assim como continuidades. Logo, a associação entre material cerâmico e os grupos descritos documentalmente faz parecer que são populações "congeladas" no tempo/espaço e que se mantiveram em suposto estado “primitivo", assim como atesta Prous (1992:51):

Primeiro, sabemos hoje que os chamados "primitivos" atuais não conservaram obrigatoriamente os traços culturais da préhistória, mas também evoluiram. Portanto, não se pode atribuir a qualquer grupo do passado algum traço cultural encontrado em etnias "primitivas" atuais. No caso brasileiro, no entanto, as condições são mais favoráveis do que na Europa, por se ter uma continuidade cultural relativa entre as culturas indígenas atuais e seus antecessores de há alguns séculos, ou porque "arquétipos" culturais tenham se mantido mais facilmente que nos paises de cultura urbana.

"Uma continuidade cultural relativa", afirma o autor, pois as sociedades indígenas no Brasil estariam em um estágio mais primitivo do que os povos europeus, dedução que outorgou a possibilidade de atribuir traços culturais pré-coloniais com base em grupos coloniais e vice-versa. Tal relação, porém, não corresponde aos fatos. Primeiro porque não há evolução, há histórias e, tanto do ponto de vista objetivo quanto do subjetivo, cada povo constrói a sua. O que temos então são culturas e histórias humanas distintas que desenvolveram modos de se relacionar com o mundo de maneiras também distintas. Não há estágios evolutivos em relação à cultura, mas sim diferenças culturais. E mesmo nesse caso as culturas sofrem transformações e mudanças constantes, mesmo nos mínimos detalhes de uma peça ou um artefato.

Por esse motivo, por que considerar Aratu-Sapucaí como Cayapó? Por uma simples e caduca oposição entre história cumulativa e história estacionária? A verdadeira história, disseram Lévi-Strauss e Eribon (1990: 160), não se encontra nos polos do modelo, mas no continuum de possibilidades que os liga.

\section{O material arqueológico não é simplista; os modelos, sim}

Desde os primeiros trabalhos que deram origem à definição da tradição Aratu-Sapucaí, como os realizados por Calderón (1969), foram encontrados junto aos cacos cerâmicos dessa tradição outros pertencentes à fase Itapicuro da tradição Tupiguarani, atestando possiveis contatos e trocas materiais e imateriais entre as duas tradições. De acordo com Caldarelli (2003), no litoral do Espírito Santo a cerâmica Aratu 
também apresentou influência Tupiguarani, pois foi utilizado banho vermelho, pintura vermelha sobre branco e decoração plástica corrugada. Soares (2013) mencionou que no Espírito Santo foi a fase Itaúnas da tradição Aratu-Sapucaí que apresentou características Tupiguarani, pois nos sítios foram encontrados "tipos cerâmicos, percebendo o tipo pintado como elemento intrusivo" (Soares 2013: 62).

Nas pesquisas realizadas em Minas Gerais e São Paulo, elementos Tupiguarani também foram associados ao material cerâmico AratuSapucaí (Alves 2009). Os principais casos são os dos sítios Água Limpa (Monte Alto, SP) e Água Branca (Casa Branca, SP). O sítio Água Limpa, estudado pela arqueóloga Márcia Angelina Alves, apresentou estruturas de combustão, sepultamentos primários e secundários, restos alimentares, cerâmica lisa e pintada de vermelho, e peças líticas lascadas, em uma dimensão espacial de aproximadamente 10.000 $\mathrm{m}^{2}$, sendo um sítio lito-cerâmico. Os dados recolhidos em campo "indicam que o sítio de Água Limpa foi ocupado até o século XVII, época coincidente com o início das Entradas e Bandeiras dos paulistas à caça de indios para escravidão" (Alves 2009: 63). A ocupação nessa área teria ocorrido de $1554 \pm 212$ anos AP até 335 anos AP e aproximadamente 6.734 peças cerâmicas foram encontradas e, de acordo com a análise em nível tecnotipológico, foram associadas à tradição Aratu-Sapucaí. Entretanto, em Água Limpa foi registrada a pintura monocromática, na cor vermelha, diretamente no vasilhame em linhas retas paralelas e horizontais, indicando influências externas. Isso também foi observado no sítio Água Branca, pois a cerâmica apresentou traços das tradições Aratu-Sapucaí, Tupiguarani e Uru, ou seja, em ambos os casos o contexto é de intensas interações culturais (Afonso 2009).

Em estudo realizado por Faccio et al. (2014) nos sítios arqueológicos Alvorada (Junqueirópolis, SP) e Piracanjuba (Piraju, SP), foram encontrados fragmentos de vasilhas duplas ou geminadas, típicas da tradição Aratu, em contexto Guarani, indicando contato entre essas populações indígenas (Fig. 1).

Esses dados demonstram que no norte do estado de São Paulo ${ }^{12}$ há uma variabilidade da cerâmica e dos contatos culturais, principalmente entre as tradições Aratu-Sapucaí e Tupiguarani, reforçando o fato de que os grupos "pré-coloniais do Brasil nunca se encontraram em imobilidade histórica, em uma condição de imutabilidade até a chegada dos europeus" (Faccio et al. 2014: 23). "Com isso, o quadro que vem se formando para a região aponta um intenso e contínuo fluxo de grupos que perpassa quaisquer hipóteses de homogeneidade desses povos" (Rasteiro 2016: 98).

O material arqueológico do Centro-Oeste não se mostra diferente quando se trata das trocas materiais e imateriais entre as tradições. Se, como mencionado, a hipótese é a de que a tradição Aratu-Sapucaí se "originou" nessa região, isso mostra que desde o início não eram grupos fechados e muito menos que havia imutabilidade cultural. De acordo com Caldarelli (2003), já no século X d.C.13 a implantação, a morfologia e o tamanho das aldeias sofrem alterações em virtude do contato com a tradição Uru, ocasionando maior diversidade da indústria cerâmica já naquele período.

A autora ainda alega que a presença de cerâmica Tupiguarani em sítios Mossâmedes seria mais um indicador do contato, "neste caso interpretado como trocas de mulheres, relacionadas a práticas de exogamia e não situações de guerra e conflito" (Caldarelli 2003: 222), sendo esse um fator importante, pois demonstra que houve alianças, interesses mútuos e formas de aparentamento entre grupos diferentes.

12 Segundo Soares (2013), isso se deve ao fato de que os estados de São Paulo, Minas Gerais, Espírito Santo e Bahia, entre outros, exceto Goiás, seriam zonas periféricas, como já apontado anteriormente, o que facilitaria as relações de contato entre diferentes tradições, muito em virtude da menor densidade das aldeias e da distância da zona central (origem).

13 Lembrando que os sítios mais antigos da tradição Aratu-Sapucaí são datados do século IX d.C. 


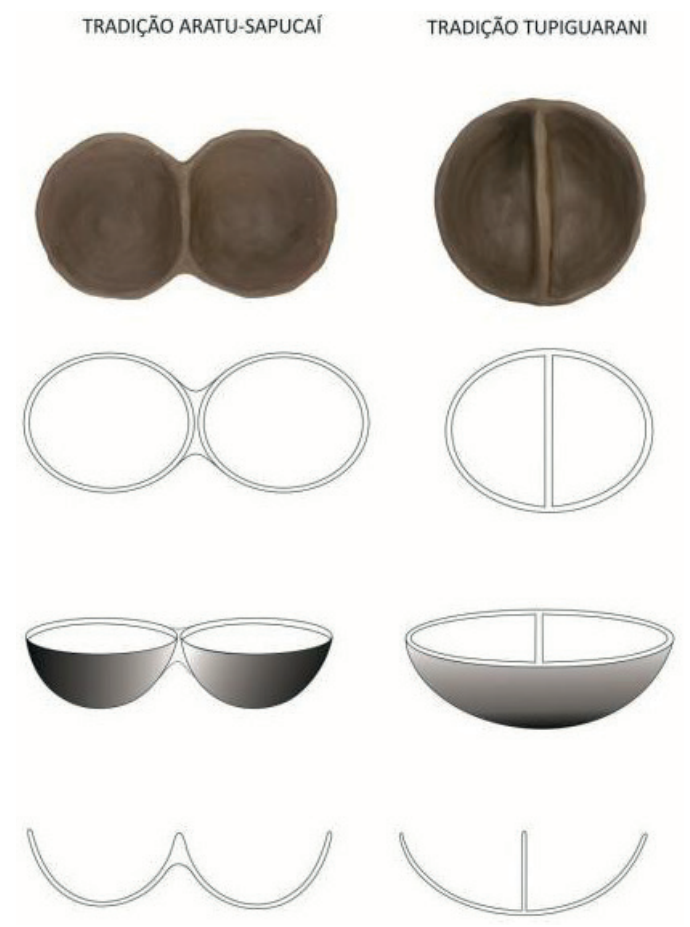

Fig. 1. Comparação entre vasos da tradição Aratu-Sapucaí (forma dupla ou geminada) e Tupiguarani (prato dividido). Fonte: Faccio et al. (2014: 14).

A presença ocasional de artefatos intrusivos indica a existência de redes extracomunitárias e extraculturais. Isso demonstra que os grupos do Centro-Oeste não eram unidades fechadas, mas propensas a constantes fluxos não só de bens como de informações e pessoas (Eremites de Oliveira EF Viana 2000: 167).

Tais relações intensas ocorreram porque, segundo Robrahn-Gonzalez (1996), a região Centro-Oeste foi uma área de confluência de grupos ceramistas que partilharam informações, objetos e/ou pessoas no período pré-colonial, ${ }^{14}$ ocasionando transformações culturais nos diferentes grupos, que acabaram por observar e desenvolver o conhecimento do cultivo e da produção da cerâmica.

14 Robrahn-Gonzalez (1996) dá o exemplo do estudo genético feito entre os Kayapó do Norte (localizados no vale do Araguaia), no qual os resultados mostraram relações genéticas com todas as populações amazônicas, sejam Caribe, Aruak ou Tupi.
Os últimos séculos antes da conquista europeia se caracterizaram, portanto, por um periodo de intensas transformações culturais, resultando no surgimento de uma série de variações locais, que passa a constituir o padrão arqueológico regional. Desta situação é que derivaria, na época do contato com o colonizador (séculos XVII e XVIII) a grande densidade e diversidade de grupos etnograficamente conhecidos (Robrahn-Gonzalez, 1996: 84).

A própria existência dos Cayapó descritos na documentação histórica afirma isso; afinal, esse é um termo guarda-chuva, não representava um único grupo, mas sim vários, que pelos interesses dos agentes coloniais acabaram classificados com base num termo único. Semelhante às tradições, os grupos coloniais foram generalizados. Nem todos os Cayapó das fontes do XVIII e XIX são de fato Cayapó, assim como também não são os Aratu-Sapucaí dos séculos IX ao XVIII porque já inseridos em outro contexto: o colonial. 


\section{Os Cayapó coloniais}

Embora alguns autores (Mead 2010: 67-77; Monteiro 1994: 63; Neme 1969: 114-117) acreditem que os Cayapó sejam conhecidos desde o século XVII como bilreiro, a primeira menção direta ao termo é da segunda década do XVIII, quando uma expedição liderada por Antonio Pires de Campos os alcança no sul de Goiás. O relato por ele deixado (Campos 1976: 181-200) desperta notável interesse à medida que desmente sucessivas alegorias usadas para descrever esses grupos a partir da década de 1730 , quando já se tem declarada contra eles uma guerra de extermínio e escravização. Nessas alegorias, os Cayapó foram descritos como "nação que não tem domicílio certo, nem plantas ou lavouras" e, por isso, "[...] se sustenta de imundices do mato" (Barros 1976: 147-148).

Ao contrário, Campos (1976: 181-182) os retratou como extremamente numerosos, sedentários e praticantes de uma agricultura desenvolvida. "[...] Este gentio é de aldeias, e povoa muita terá por ser muita gente [...] estes vivem de suas lavouras, e no que mais se fundam são batatas, ${ }^{15}$ milho e outros legumes". Além disso, nessa descrição eles foram apresentados como detentores de uma organização sociopolítica elaborada, na qual "cada aldeia tem seu cacique, que é o mesmo que governador a que no estado de Maranhão chamam principal, a qual os domina" (Campos 1976: 182).

Então, se desde o início dos contatos podemos crer que esses grupos eram numerosos, sedentários, praticantes de uma agricultura intensiva e organizados em aldeias com estrutura política e social elaborada, por que foram descritos nas fontes históricas como o oposto disso? Parte da resposta a essa pergunta talvez esteja em pensar as alegorias com base nas representações e nas condições pragmáticas em que se deram os contatos. Se em alguns pontos as fontes são contraditórias entre si, em um ponto crucial elas são unânimes: esses grupos eram extremamente aguerridos e fizeram da guerra

15 A batata foi identificada pela moderna etnografia (Galvão 1979: 232) como o principal alimento cultivado pelos povos indígenas do Brasil central. sua forma preferencial de relação com algumas de suas alteridades. Em diferentes momentos do XVIII, e mesmo na descrição daquele primeiro encontro, os documentos históricos repetiram sobre esses grupos Cayapó a mesma narrativa: "[...] tudo levam de traição e rapina [...] e prezarem-se muito entre eles a quem mais gente há de matar [...]" (Campos 1976: 182); "[...] guerreiam com traição" (Barros 1976: 148-149); são o "mais traidor de todos" (Camello 1976: 115); "[...] havendose com tão bárbara crueldade, que nem as crianças perdoam, nem dão quartel a pessoa alguma" (DI $\left.{ }^{16} 22: 185\right)$.

A índole guerreira desses grupos indígenas, quando acionada num contexto colonial, serviu para eles serem enquadrados pelas políticas indigenistas do período na categoria de índios hostis, inimigos, habitantes dos sertões, não administrados, não catequizados e, portanto, sobre os quais se voltaram os agentes e a administração colonial. A partir de 1730, declara-se contra eles uma guerra de extermínio e escravização camuflada sob o discurso e a noção de guerra justa, uma prerrogativa que aparece em diferentes contextos como o modus operandi do império ultramarino português. Nas ordens dos governadores anunciava-se a barbárie: "[...] não se rendendo os ditos Gentios, e sendo tomado as mãos na pelleja os passarão a espada sem distinção ou differença de sexo" (DI 22: 168).

Portanto, foi em correlação com esse contexto pragmático de guerras que a administração colonial e seus agentes construíram as representações desses grupos indígenas durante o século XVIII. É por isso que o termo Cayapó, tal como os termos Guayaná, Coroado e Tapuia, pode ser associado a um apelativo genérico que abrangia quaisquer grupos que possuíam com eles similaridades, tais como ter língua diversa da geral, habitar os sertões, serem aguerridos e constarem como empecilho ao acesso às minas do Centro-Oeste. Confirma isso o fato de Cayapó não ser uma etnonímia, mas palavra de origem Tupi ou Guarani que significa “como macaco" (Turner 1992: 311),

16 Abreviatura aqui e doravante utilizada para a série de publicação dos Documentos interessantes para a história e costumes de São Paulo (Arquivo Público do Estado de São Paulo 1913). 
representação que, a partir da visão colonial, os aproximava definitivamente da "selvageria".

Cunhado no contexto dos confrontos com os índios dos sertões, o termo Cayapó foi uma construção colonial e uma atribuição artificial de etnicidade e de fronteira que não corresponde a uma realidade, pois foi um termo que passou a ser usado indistintamente para descrever ou narrar fatos associados aos genéricos índios dos sertões. Mesmo os governadores em suas ordens de guerra escreveram para atacarem o "Gentio bárbaro da nação Cayapó, e os mais q.'infestão o caminho [...] emthé as minas de Goiaz" (DI 22: 168). Ocultados como "os mais", esses outros grupos autóctones são raramente mencionados. Todavia, ainda que esparsos dentro de uma ampla documentação histórica, todos os termos utilizados para se referir aos índios dos sertões - Cayapó, Araxá, Xavante, Xakriabá e Akroá (Mano 2015) podem ser identificados modernamente como grupos indígenas da família dos Jê. O Cayapó constitui uma língua homônima da família Jê do tronco Macro-Jê, e os Akroá, hoje extintos, falavam a língua akuen (Apolinário 2003: 86), mesma língua falada pelos Xakriabá e Xavante, também considerada uma língua da família Jê do tronco Macro-Jê (Rodrigues 2002).

A considerar ainda que parte desses grupos dos Cayapó meridionais são os atuais Panará (Kreen-Akarôre) (Giraldin 1997; Heelas 1979) estão abertas as vias de relação dos grupos registrados nas fontes do século XVIII com o universo de diferentes grupos indígenas dos Jê setentrionais e/ou centrais.

Em face desses dados históricos, parece ser bastante problemática a associação nessa região entre a tradição Aratu-Sapucaí e os Cayapó mencionados na documentação histórica. Não fosse apenas a distância temporal que colocam esses grupos em contextos históricos completamente diferentes, os Cayapó das fontes podem, de fato, ser uma infinidade de grupos indígenas do tronco linguístico Macro-Jê.

Além disso, diferentemente dos grupos produtores de artefatos cerâmicos da tradição Aratu-Sapucaí, os grupos mencionados nos documentos do século XVIII já se encontravam em situação colonial, um ambiente marcado por intensos contatos desses grupos com diferentes alteridades, e com os quais estabeleceram uma rede trançada por diferentes estratégias de ação. Por meio delas fizeram afluir do mundo exterior uma série de elementos que podem ter servido para renovar o arsenal de técnicas, materiais e estilos de produção cerâmica e, nesse caso, elementos ou técnicas encontrados em sítios datados do período histórico devem ser pensados não como continuidade de um passado remoto, mas como o registro físico desses inevitáveis encontros e intercâmbios variados.

Para os grupos Cayapó que no século XVIII transitavam pela região dos atuais Triângulo Mineiro, Alto Paranaíba, sul de Goiás e norte de São Paulo já se tem traçada uma ampla rede de contatos que eles estabeleceram com diferentes outros. Uma rápida explanação de alguns desses encontros servirá para mostrar a complexa, rica e intricada teia de relações e estratégias por meio das quais, ao longo dessa história, esses grupos indígenas incorporaram pessoas, conhecimentos, bens simbólicos e bens materiais que certamente devem ter renovado e reformulado o seu arsenal cultural. Entre essas alteridades em choque e em intersecção com os Cayapó no século XVIII estavam não índios, outros grupos indígenas, índios aldeados, mestiços e negros (escravos, forros e fugidos).

\section{Os Cayapó e seus outros: apropriações e incorporações}

Com relação aos não índios, embora não pareça ter ocorrido nenhum incidente de beligerância no primeiro contato, desde a década de 1720 grupos Cayapó passaram a ser culpados de cometer ataques, roubos e assassinatos nas vilas, lavras e estradas das minas. Nesses ataques, os guerreiros Cayapó se apresentavam sempre bravos, ferozes, agindo "com tão bárbara crueldade e sua costumeira ferocidade" (Arquivo Histórico Ultramarino 1751: cx. 2, doc. 179) matando a todos e sem fazer cativos, porque "nem dão quartel a pessoa alguma” (DI 22: 185). Queimavam as propriedades imóveis e levavam os espólios da guerra: bens materiais móveis descritos 
nos documentos com os termos "roubando os viajantes" e "levando os despojos" (Arquivo Histórico Ultramarino 1751: cx. 20 doc. 1220). Portanto, nas relações com os não índios usaram guerras nas quais matavam todos e roubavam os bens materiais móveis (Mano 2012; Rodrigues 2011). Posteriormente, com esses mesmos não índios fizeram as "pazes" e passaram a se relacionar por vias do comércio e das políticas de aldeamento. Nesse período são descritivos como "[...] povos sem fereza [...] qe. ha m.to tempo não fazem mal aos negociantes, [...] fallão e familiarm.te tractão com a nossa gente, aqm. pedem muitas coizas, e tãobem dão outras" (DI 3: 106-107). Apesar da aparente pacificação, o certo é que, de maneira intencional e politicamente orientada, com essas estratégias eles continuaram a fazer afluir para o mundo interior bens materiais que antes conseguiam apenas via butim (Asnis 2019; Mano 2011). Nesse sentido, seja por guerras, por comércio ou por negociação do aldeamento, os grupos Cayapó coloniais constantemente sacaram dos não índios elementos técnicos, estéticos e materiais que passaram a fazer parte do repertório de sua tradição.

Nas relações históricas de contato com os não indios, os documentos mostram que eles sempre conquistaram elementos materiais, mas nunca incorporaram pessoas. Enquanto isso, nas relações com outros grupos indígenas fizeram guerras, roubaram bens materiais e capturaram mulheres e crianças. Já no primeiro registro de 1723, Campos (1976: 182) escreveu: "[...] e seu maior exercício é serem corsários de outros gentios de várias nações [...] e nos assaltos que dão aqui e presas que fazem reservam os pequenos que criam para seus cativos". Em outros relatos documentais, os Cayapó são acusados de atacar grupos de índios Araxá que viviam no rio Grande, no caminho que levava às minas de Goiás. Nesses assaltos eles mataram todos os homens e levaram cativas as mulheres e crianças (Arquivo Histórico Ultramarino 1751: cx. 6, doc. 465). Histórica e etnograficamente, as guerras dos grupos Jê contra outros grupos aparentados ou não linguisticamente foram fartamente descritas (Gordon 2006; Verswijver 1992; Vidal 1977) e, normalmente nelas constavam capturas de jovens mulheres. Nas guerras dos Jê Xikrin contra grupos
Gorotirê, "um dos objetivos [...] era roubar crianças e mulheres. As crianças capturadas eram adotadas e submetidas ao processo de socialização como qualquer outra criança. [...] Homens adultos eram mortos, nunca aprisionados" (Vidal 1977: 46). Nesse caso, e entre os Cayapó coloniais, os contatos históricos com outros grupos indígenas fizeram circular não só coisas, mas pessoas. Seja por aparentamento, adoção, afinização ou apenas por um convívio temporário, mulheres tomadas de outros grupos indígenas serviram para fazer circular conhecimentos, saberes e fazeres. Cantos, nomes, danças, cerimônias, técnicas e conhecimentos eram, por assim dizer, apreendidos e incorporados pelos cativadores e isso pode, obviamente, ter impactado técnicas, estilos, formas e características de objetos e artefatos materiais.

Ao longo dessa história dos contatos os grupos Cayapó também foram expostos a índios de diferentes etnias (Bororo, Javaé, Kurumaré, Xakriaba, Paresi, Akroá e Karajá, entre outros) transferidos de outras partes da colônia e aldeados no Triângulo Mineiro. A estratégia de assentar esses índios no caminho de Goiás era parte da política indigenista para dar fim aos ataques e insultos dos Cayapó. Lideradas por Antonio Pires de Campos (o mesmo que pela primeira vez usou o termo Cayapó), essas tropas causaram impactos irreversíveis a esses grupos. Estima-se que em um só ano aproximadamente 8.000 Cayapó tenham sido escravizados (Karasch 1997: 33). A escravização, a depopulação, as fugas de suas aldeias e a abrupta desarticulação social, política e econômica teve consequências drásticas para o regime de produção e reprodução social desses grupos, e esse processo já não poderia ser igual ou semelhante ao do período précolonial. Parece sensato pensar que uma comparação entre sítios arqueológicos datados de períodos históricos diferentes deva registrar não uma continuidade, mas processos de desterritorialização movidos por deslocamentos forçados ou voluntários, a diminuição da população e do tamanho dos assentamentos e a mudança nos espaços de ocupação.

Além disso, as características técnicas e estéticas dos objetos e artefatos que possam vir a brotar desses antigos aldeamentos, ou mesmo daqueles 
onde mais tarde foram aldeados os Cayapó - como o Maria I em 1781 -, não podem ser atribuídos a uma suposta tecnologia desses grupos, sejam eles quais forem. Nos interstícios desses aldeamentos, a sociocosmologia e as formas de sociabilidade tiveram de ser constantemente negociadas entre sujeitos de várias etnias indígenas e, entre eles, $\mathrm{e}$ os não indígenas. Nesses novos espaços sociais, a exemplo de aldeias coloniais em diferentes regiões do Brasil (Almeida 2013; Carvalho Junior 2005; Monteiro 2001), a multiplicidade de sujeitos, signos e interesses em negociação formaram os ingredientes para o surgimento de um novo coletivo, cujas formas de sociabilidade, organização e cultura foram híbridas.

Não só os indígenas aldeados criaram vínculos sociais e culturais entre si, muitas vezes à revelia da administração colonial: os sertanistas, para adentrar à lógica política indígena, também se adaptaram ao seu modo de vida e praticavam, também à revelia das autoridades, poligamia, concubinato e adesão a determinados valores indígenas (Monteiro 1994: 36). Para dar conta dessa nova realidade, alguns autores já denominaram esses índios dos aldeamentos como índios coloniais (Spalding 1982), índios misturados (Pacheco de Oliveira 1998, 2016), índios cristãos (Carvalho Junior 2005) etc., e a história indígena já demonstrou como em cada caso particular esses coletivos mantiveram uma identidade e um comportamento diferenciado dentro da sociedade colonial.

O resultado inesperado da política indigenista dos aldeamentos foi a etnogênese, a emergência de um índio novo. Um século mais tarde, durante a primeira metade do XIX, esse índio novo ainda incorporava nos aldeamentos vários outros, a ponto de viajantes relatarem que nas aldeias indígenas do Triângulo Mineiro só havia mestiços, índios casados com negros, índios com portugueses (Saint-Hilaire 1975; Spix \& Martius 1981). Por isso, uma arqueologia desses aldeamentos deve revelar não uma continuidade ou uma nova fase da tradição, porque isso seria esquecer e negligenciar os fluxos históricos e as dinâmicas culturais das quais a cultura material deve ser a evidência física.
Finalmente, mas não por fim, a história dos contatos dos grupos Cayapó no século XVIII incluiu ainda negros fugidos da escravidão. A partir da década de 1730 se proliferou no interior das minas de Goiás e Minas Gerais uma série de comunidades autônomas que os documentos da época tratam como quilombos e "calhambolas" (Amantino 2001; Barbosa 1971; Mano 2015; Souza 2004). No sentido leste-oeste de Minas, cruzando o alto rio São Francisco e a serra da Canastra em direção ao atual Triângulo Mineiro e sul de Goiás, a itinerância desses grupos fez pipocar pela região uma série dessas comunidades. A farta documentação histórica que faz referência a esses quilombos usa constantemente os superlativos de "são muitos", "multidão", "grande grandeza", "semelhante à dos Palmares na sua multidão" (Mano 2015: 527-528) para fazer referência aos negros fugidos e acoitados na região. Eram conhecidos nominalmente na documentação oficial mais de uma dezena dessas comunidades, ${ }^{17}$ algumas das quais contando com "seiscentos negros armados [...] e seis alqueires de milho" (Arquivo Público Mineiro 1743-1749). Tratadas como quilombos, essas comunidades atraíam toda a sorte de indivíduos das camadas mais baixas da sociedade colonial: pretos forros, homens livres pobres, negros escravos e índios.

Em tais circunstâncias, os grupos indígenas identificados nas fontes como Cayapó, que também estavam nesse período em fuga de suas aldeias, entraram inevitavelmente em contato com essas comunidades. Segundo as fontes, em muitos casos houve entre esses dois coletivos alianças e trocas mútuas, alicerçadas na defesa de interesses comuns num cenário de intensos conflitos e negociações (Alves 2017; Mano 2015; Mano \& Alves 2015). Outros autores (Amantino 2001; Lourenço 2005) já chamaram a atenção para relações entre índios e negros a

17 Na documentação compulsada aparecem nominalmente os quilombos do Ambrosio e Queimado, no alto rio São Francisco; o do Andaial, próximo ao município de Araxá; o Zundu, ao sul do rio Grande; o do Catigua, no rio Quebra Anzol (afluente do Paranaíba); além dos quilombos Grande, Cascalho, Bambui, Sambabaya, Corisco, São Gonçalo, Corumbá, Santa Fé e Jacuí entre outros (Mano 2015). 
partir da identificação de influências indígenas nos modos de adaptação das populações dos quilombos. Mais recentemente, provas documentais sugerem que essa relação ia além da troca de saberes e conhecimentos, em direção ao convívio mútuo e defesas comuns.

Em 1760, um ataque oficial a um desses quilombos foi repelido "por uma grande povoação de gentio que intensamente os rebateu com um grande número de flechas" (Mano 2015: 538-539). Os "quilombos", essas grandes e complexas agremiações, pareciam formar uma rede bem organizada, que pelo volume e estrutura dificilmente teriam existido sem uma rede de relações e alianças com sujeitos de outras camadas da sociedade colonial. Os quilombos foram espaços de trocas econômicas, políticas, sociais, culturais e simbólicas entre índios, homens livres pobres, comerciantes, negros etc. Se é certo que a tecnologia dos quilombos teve influências indígenas e de setores pobres da sociedade colonial, deve ser certo, também, que a tecnologia indígena nesse período absorveu elementos de tradição negra e da população mestiça pobre.

Novamente aqui, do ponto de vista de sua história, de sua tecnologia, de sua cultura, de suas formas de sociabilidade, de seus regimes simbólicos e de suas ações políticas, os Cayapó da documentação colonial, ao contrário dos grupos pré-coloniais, estão dispostos a uma intensa rede de contatos que desenhava trânsitos constantes de pessoas, saberes, técnicas, conhecimentos, numa dinâmica cultural nunca antes vista. Apesar de as formas e o conteúdo das relações serem diversos, a depender dos sujeitos, dos signos, dos interesses, do momento histórico e das circunstâncias envolvidas, em todas elas parece certo propor que os grupos Cayapó realizaram uma abertura para o mundo exterior e uma incorporação constante de novos elementos. Guerra, rapto, roubo, negociação, aparentamento, trocas comerciais, convivência mútua, entre outros, serviram para fazer circular pessoas, bens materiais e bens simbólicos que se tornariam renovadores da tradição.

Assim, quando se pensa num possível desenho para essa história dos contatos, fica claro que ela não traçou uma linha reta que levou da tradição aos Cayapó coloniais. Ao contrário, essa história foi feita de bifurcações, recuos, conexões e desconexões em redes não estruturadas, cuja representação aproximada seria a de uma mandala. Como ela, essa história é feita de encontros e imbricações de diferentes arranjos; e "cada ponto de intersecção possivel pode gerar mesclas hibridas e sobreposições de duas, três, quatro ou mais possibilidades, todas não necessariamente duradouras [...]" (Mano 2018: 27). Nesses encontros constroem-se fronteiras híbridas e porosas (Barth 1998) - ou "entre-lugares" (Bhabha 1998) - nas quais se operam mistos de continuidade e ruptura, de permanência e mudança, de tradição e modernidade, de identificação e diferenciação. Dessa perspectiva, os dados impõem pensar a cultura como dinâmica, constantemente adaptada às situações vivenciadas pelos grupos e, por isso, grupos étnicos e identidades de grupo são relativas e mutantes, porque a transformação da cultura também é um modo de sua reprodução (Sahlins 1990: 2008).

\section{[...] Ao contrário [dos tradicionais} modelos fixos baseados em estruturas binárias dicotômicas] o modelo em forma de mandala expressa a descentralização, enfatiza as interfaces entre os diferentes sujeitos, categorias e contextos envolvidos nas relações de contatos, e enfoca processos contínuos e cambiantes de criação/destruição/recriação de fronteiras culturais porosas onde se cruzam, se sobrepõem, se retraem e se expandem uma multiplicidade de agenciamentos históricos (Mano 2018: 27).

Uma história baseada no protagonismo e na ação política consciente dos indígenas sugere que uma possível história desses grupos Cayapó tenha sido cambiante, mutante.

Não traçou linhas retas, mas constituiu redes não estruturadas, ramificações e trajetos que resultaram, às vezes, em mesclas inesperadas. Em face desses dados, os registros arqueológicos do período histórico não devem revelar uma continuidade com o passado, assim como os indígenas das fontes documentais não podem servir para pensar de forma direta e acrítica o 
registro arqueológico pré-colonial. É certo que o passado nunca é definitivamente superado, mas é certo também que ele é permanentemente renovado. Isso implica pensar menos na continuidade histórica entre tradição AratuSapucaí e grupo indígena Cayapó e mais no fato de que a cultura material, em sua condição de suscetibilidade à empréstimos, inovações, aquisições e imitações, pode ser uma evidência física das dinâmicas culturais e dos processos históricos de contatos.

\section{Considerações finais}

Se o trajeto que leva da tradição AratuSapucaí aos grupos Cayapó ainda não está totalmente interrompido, várias barreiras já se levantaram nesse caminho. Em vez de uma continuidade estática de um povo ou etnia, os dados apontam para processos dinâmicos de intersecções culturais acionadas pelos indivíduos ao longo de sua história, esses mesmos indivíduos que fabricaram, usaram e fizeram circular artefatos. $O$ contexto dos objetos pode ser ambiental, tipológico, funcional, cultural, mas mesmo esses contextos e, por isso, os próprios objetos - também são históricos. Devem, pois, ser colocados nos processos de produção e circulação que começam com a práxis oleira e terminam no descarte ou destino final do objeto, passando por todas as aproximações e possibilidades de sua fabricação e uso, pertencendo simultaneamente ao campo da tradição e das transformações que sofreram oleiras, usuários e objetos ao longo de suas histórias.

Está claro, como já mostrou Lévi-Strauss (2004) para as pinturas faciais dos Kadiwéu, que a originalidade não está nos motivos, mas em sua combinação. Eles são dados pela tradição, por uma estrutura e um jogo de possibilidades. No entanto, é preciso pensar, como esse mesmo autor (Lévi-Strauss 1989: 210), que é por colaboração entre tradição e invenção que se produz e se modifica uma estrutura.

O exemplo do feiticeiro incrédulo pode ser o da oleira, que passa a inventar e promover novas técnicas e elementos. Desse ponto de vista, não há oposição entre tradição e modernidade, há reformulação permanente.

Com base nos dados aqui apresentados, $\mathrm{o}$ arsenal de possibilidades pode vir a ser renovado tanto pela inovação interna e capacidade criativa dos indivíduos quanto pelas relações com o mundo exterior. Como vimos, os Cayapó históricos tiveram de se relacionar com diferentes alteridades e o fizeram por meio de diferentes estratégias, como guerras, raptos, roubos, negociações, aparentamentos, trocas comerciais, convivências mútuas etc., que serviram para fazer circular em rede pessoas, bens materiais e bens simbólicos renovadores da tradição.

Parece óbvio que a continuidade e as transformações das tradições não obedeceram, necessariamente, a um ritmo constante e geral. Isso envolve processos históricos complexos de persistência, transformação, contatos, mudanças de direções, debates, cismas, diferentes linhas de atuação e diferentes destinos históricos. Poder-se-ia dizer, uma história imprevisível, porém não arbitrária porque desenhada sobre condições concretas. O desenho dessa história não pode ser o de uma linha reta, estágios ou oposição entre aculturação e resistência. Talvez seja melhor pensá-la como composta por uma multiplicidade de caminhos conectados em redes não estruturadas, semelhante à mandala e aos rizomas (Deleuze \& Guatarri 2011). É nessa rede que circulam tradições e invenções de todos os envolvidos, resultando, por todos os lados e direções, em fluxos de estilos, técnicas, saberes etc. não originalmente próprios ou seus, mas apropriados, combinados, testados e misturados com os seus. 
ASNIS, G.Z.P.; MANO, M. Continuities and discontinuities: Aratu-Sapucaí archeology and the Cayapó indigenous history. R. Museu Arq. Etn. 34: 154-173, 2020.

\begin{abstract}
This article analyzes the direct and critical associations between ceramist groups of the Aratu-Sapucaí archaeological tradition and groups known in the documentation as Cayapó. In the regions of the Triângulo Mineiro, upper Paranaiba, southern Goiás and northern São Paulo, the spatio-temporal overlap of occupations by groups with that tradition and those mentioned in the sources allowed for the proposal of a cultural continuity among historically distant peoples. The image of linear history and of a fossilized culture is obtuse to how indigenous people were described in a colonial situation according to historical documents, an environment marked by tension and conflicts of interests. Both archaeological and documentary data insist on showing constant contact and transformation. Fossil records of this tradition point to influences from other transformations; and documentary records of the Cayapó show a complex and intricate network of relationships with varying types of alterity. Therefore, both the history of the Aratu-Sapucaí ceramics producing groups and the colonial "Cayapó" cannot be thought of as isolated, but composed of porous borders in which they expanded, retracted and overlapped a series of assemblages. In those boundaries shaped by contacts, people, symbolic goods, materials, knowledge, and techniques, carried on unstructured networks, have gone through unstructured networks with direct and indirect effects in traditions to the point of renewal. Under these conditions, archaeological artifacts should be the physical record of these changes and not evidence of continuity. The article then mobilizes utilizes data from archeology, indigenous history and anthropology with the purpose of raising barriers in the path leading groups belonging to the pre-colonial past to land in the context of the Brazilian colony, or vice-versa.
\end{abstract}

Keywords: Aratu-Sapucaí; Cayapó; Mossâmedes; Archaeological traditions; Contact history.

\title{
Referências bibliográficas
}

Afonso, M. C. 2009. Um painel da arqueologia pré-histórica no estado de São Paulo: os sítios cerâmicos. Especiaria (UESC) 11(12): 127-155.

Almeida, M.R.C. 2013. Metamorfoses indígenas: identidade e cultura nas aldeias coloniais do Rio de Janeiro. 2. ed. Editora FGV, Rio de Janeiro.

Alves, D.S. 2017. Do alto da espia: gentios, calhambolas e vadios no sertão do Campo Grandeséculo XVIII. Dissertação de mestrado. Universidade Federal de Uberlândia, Uberlândia.
Alves, M.A. 1992. As estruturas arqueológicas do Alto Paranaíba e Triângulo Mineiro - Minas Gerais. Revista do Museu de Arqueologia e Etnologia 2: 27-47.

Alves, M.A. 2009. Assentamentos e cultura material indígena anteriores ao contato no Sertão da Farinha Podre, MG, e Monte Alto, SP. Tese de livredocência. Universidade de São Paulo, São Paulo.

Amantino, M. 2001. O mundo das feras: os moradores do Sertão Oeste de Minas Gerais - Século XVIII. 
Continuidades e descontinuidades: a arqueologia Aratu-Sapucaí e a história indígena Cayapó

R. Museu Arq. Etn., 34: 154-173, 2020.

Tese de doutorado. Universidade Federal do Rio de Janeiro, Rio de Janeiro.

Apolinário, J. R. 2003. A saga dos Akroá nas fronteiras do sertão. Tellus 3(5): 83-94.

Asnis, G.Z.P. 2019. Da guerra à paz? Dicotomias que escondem múltiplos caminhos: análise histórica dos "Cayapó" aldeados em Maria I e São José de Mossâmedes. Dissertação de mestrado. Universidade Federal de Uberlândia, Uberlândia.

Ataídes, J.M. 1998. Sob o signo da violência: colonizadores e Kayapó do Sul no Brasil Central. UCG, Goiânia.

Barbosa, W.A. 1971. A decadência das minas e a fuga da mineração. Editora da UFMG, Belo Horizonte.

Barth, F. 1998. Grupos étnicos e suas fronteiras. Editora da UNESP, São Paulo.

Bhabha, H. 1998. O local da cultura. Editora da UFMG, Belo Horizonte.

Brochado, J.P. 1991. Um modelo ecológico de difusão da cerâmica e da agricultura no leste da América do Sul. In: Anais do I simpósio de pré-história do Nordeste brasileiro, 1991, Recife: 85-88.

Caldarelli, S.B. 2003. Arqueologia do Vale do Paraíba Paulista: SP-070 Rodovia Carvalho Pinto. Disponível em: <https://bit.ly/312EgsG $>$. Acesso em: 29 jul. 2020.

Calderón, V. 1969. A fase Aratu no Recôncavo e litoral norte do estado da Bahia. Publicações Avulsas do Museu Paraense Emílio Goeldi 13: 161-172.

Carvalho Junior, A.D. 2015. Índios cristãos: $a$ conversão dos gentios na Amazônia Portuguesa
(1653-1769). Tese de doutorado. Universidade Estadual de Campinas, Campinas.

Deleuze, G.; Guatarri, F. 2011. Mil platôs: capitalismo e esquizofrenia. v. 1 Editora 34, São Paulo.

Eremites de Oliveira, J. 2016. Etnoarqueologia, colonialismo, patrimônio arqueológico e cemitérios Kaiowá no Estado de Mato Grosso do Sul, Brasil. Revista de Arqueologia 29(1): 136-160.

Eremites de Oliveira, J. 2017. Revisitando uma discussão sobre arqueologia, identidade étnica e direitos territoriais dos povos indígenas no Brasil. In: Campos, J.B.; Rodrigues, M.H.S.; Funari, P.P. (Orgs.). A multivocalidade da arqueologia pública no Brasil: comunidades, práticas e direitos. EdiUnesc, Criciúma, 32-75.

Eremites de Oliveira, J.; Viana, S.A. 2000. O CentroOeste antes de Cabral. Revista USP 44(1): 142-189.

Faccio, N.B. et al. 2014. Vasilhas duplas Aratu (MacroJê) em Sítio Tupi-Guarani: evidência de contato? Revista Ágora 20: 6-23.

Fagundes, M. 2015. Histórico das pesquisas arqueológicas no Triângulo Mineiro. In: Ferreira Filho, A. (Org.). Índios do Triângulo Mineiro. EDUFU, Uberlândia, 99-144.

Galvão, E. 1979. Encontro de sociedades: índios e brancos no Brasil. Rio de Janeiro: Zahar.

Giraldin, O. 1997. Cayapó e Panará: luta e sobrevivência de um povo Jê do Brasil central. Editora da Unicamp, Campinas.

Gordon, C. 2006. Economia selvagem: ritual e mercadoria entre os Xikrin Mebêngôkre. Editora Universitária Unesp/ISA, São Paulo. 
Heelas, R. 1979. The social organisation of the Panará, a Gê tribe of Central Brazil. Phd. Tese de doutorado. St. Catherine's College, Oxford.

Jones, S. 1997. The archaeology of ethnicity: constructing identities in the past and present. Routledge, Londres.

Karasch, M. 1997. Conflito e resistência inter-étnicos na fronteira brasileira de Goiás, nos anos 1750 a 1780. Revista da SBPH 12: 31-49.

Lévi-Strauss, C. 1989. Antropologia estrutural. Tempo Brasileiro, Rio de Janeiro.

Lévi-Strauss, C. 2004. Tristes trópicos. Companhia das Letras, São Paulo.

Lévi-Strauss, C.; Eribon, D. 1990. De perto e de longe. Nova Fronteira, Rio de Janeiro.

Lourenço, L.A.B. 2005. A oeste das minas: escravos, índios e homens livres numa fronteira oitocentista - Triângulo Mineiro (1750-1861). EDUFU, Uberlândia.

Mano, M. 2011. Contato, guerra e paz: problemas de tempo, mito e história. Trabalho \& Política 29(34): 193-212.

Mano, M. 2012. Sobre as penas do gavião mítico: história e cultura entre os Kayapó. Tellus 12(22): 133-154.

Mano, M. 2015. Índios e negros nos sertões das minas: contatos e identidades. Varia história 31(56): 511-546.

Mano, M. 2018. Da tradição à cultura: problemas de investigação nos estudos das ocupações humanas no Planalto Meridional Brasileiro. Albuquerque: Revista de História 10(19): 8-34.

Mano, M.; Alves, D.S. 2015. Nos bastidores da História: o contato entre índios e negros no século XVIII. Cadernos de Pesquisa do CDHIS 28: 217-235.
Mead, D. 2010. Caiapó do Sul: an etnohistory (1610 - 1920). Tese de pós-doutorado. University of Florida, Gainesville.

Monteiro, J.M. 1994. Negros da terra: bandeirantes e índios na formação de São Paulo. Companhia das Letras, São Paulo.

Monteiro, J.M. 2001. Tupis, tapuias e historiadores: estudos de história indígena e do indigenismo. Tese de livre docência. Universidade Estadual de Campinas, Campinas.

Neme, M. 1969. Dados para a história dos índios Caiapó. Anais do Museu Paulista 23: 101-147.

Nimuendajú, C. 2002. Mapa etno-histórico/IBGE. IBGE, Rio de Janeiro; Brasília, Ministério da Educação.

Pacheco de Oliveira, J. 1998. Uma etnologia dos "índios misturados"? Situação colonial, territorialização e fluxos culturais. Mana 4(1): 47-77.

Pacheco de Oliveira, J. 2016. O nascimento do Brasile outros ensaios: "pacificação", regime tutelar e formação de alteridades. Contra Capa, Rio de Janeiro.

Prous, A. 1992. Arqueologia brasileira. Editora da Universidade de Brasília, Brasília.

Rasteiro, R.P. 2016. Arqueologia Jê no sertão paulista: os Kayapó Meridionais na bacia do Rio Grande SP. Revista do Museu de Arqueologia e Etnologia 27: 90-102.

Rice, P.M. 1987. Pottery analysis. Londres, University of Chicago Press.

Robrahn-Gonzalez, E.M. 1996. Os grupos ceramistas pré-coloniais do Centro-Oeste brasileiro. Revista do Museu de Arqueologia e Etnologia 6: 83-121.

Robrahn-Gonzalez, E.M. 2001. As aldeias circulares do Brasil Central: Brasil 50 mil anos - Uma viagem ao passado pré-colonial. EDUSP; MAE-USP, São Paulo. 
Continuidades e descontinuidades: a arqueologia Aratu-Sapucaí e a história indígena Cayapó

R. Museu Arq. Etn., 34: 154-173, 2020.

Rodrigues, A. 2002. Línguas brasileiras: para o conhecimento das línguas indígenas no Brasil. Loyola, São Paulo.

Rodrigues, Á.A. 2011. Contato e guerra: etno-história de um gentio Cayapó. Dissertação de mestrado. Universidade Federal de Uberlândia, Uberlândia.

Sahlins, M. 1990. Ilhas de história. Jorge Zahar, Rio de Janeiro.

Sahlins, M. 2008. Metáforas históricas e realidades míticas: estrutura nos primórdios da história no reino das Ilhas Sandwich. Jorge Zahar, Rio de Janeiro.

Saint-Hilaire, A. 1975. Viagem à província de Goiás. Itatiaia, Belo Horizonte; Edusp, São Paulo.

Schiavetto, S.N.O. 2005. A questão étnica no discurso arqueológico: afirmação de uma identidade indígena minoritária ou inserção na identidade nacional. In: Funari, P.P.A.; Orser Júnior, C.; Schiavetto, S.N.O. Identidade, discurso e poder: estudos de Arqueologia contemporânea. Annablume; Fapesp, São Paulo, 77-90.

Schmitz, P.I. et al. 1982. Arqueologia do CentroSul de Goiás: uma fronteira de horticultores indígenas no centro do Brasil. Pesquisas, Antropologia 33. São Leopoldo: Instituto Anchietano de Pesquisas Unisinos.

Silva, F.A. 2002. Mito e arqueologia: a interpretação dos Asurini do Xingu sobre os vestígios arqueológicos encontrados no parque indígena Kuatinemu Pará. Horizontes Antropológicos 8(18): 175-187.

Soares, J. 2012. Discutindo a tradição Aratu: o sítio cerâmico GO-RV-06 e novas contribuições. Dissertação de mestrado. Universidade do Vale do Rio dos Sinos, São Leopoldo.

Soares, J. 2013. Discutindo a tradição Aratu: proposta de um modelo de dispersão e implantação nas zonas de tensão ecológica. Revista do Museu de Arqueologia e Etnologia 23: 61-77.

Souza, L.M. 2004. Desclassificados do ouro: a pobreza mineira no século XVIII. 4. ed. Graal, Rio de Janeiro.

Spalding, K. 1982. Essays in the political, economic, and social history colonial Latin America. University of Delaware Press, Newark.

Spix, J.B.; Martius, K. 1981. Viagem pelo Brasil (1817-1820). Edusp, São Paulo.

Tomaso, I.; Lima Filho, M.F. (Orgs.). 2012. Antropologia e patrimônio cultural. ABA Publicações, Brasília.

Turner, T. 1992. Os Mebengokre Kayapó: história e mudança social, de comunidades autônomas para a coexistência interétnica. In: Carneiro da Cunha, M. (Org.). História dos índios no Brasil. Companhia das Letras, São Paulo, 311-338.

Velden, F.V. 2018. Cacos de espíritos: aproximações entre Arqueologia e Antropologia no caso Karitiana em Rondônia. Amazônica: Revista de Antropologia 10(1): 182-208.

Verswijver, G. 1992. The club-figthers of the Amazon: Warfare among the Kayapó Indians of Central Brazil. Rijksuniversiteit te Gent, Gent.

Vidal, L.B. 1977. Morte e vida de uma sociedade indígena brasileira: os Kayapó-Xikrin do rio Catete. Hucitec, São Paulo.

Wüst, I.; Barreto, C. 1999. The ring villages of Central Brazil: a challenge for Amazonian Archaeology. Latin American Antiquity 10(1): 3-23.

Wüst, I.; Carvalho, H.B. 1996. Novas perspectivas para o estudo dos ceramistas pré-coloniais do Centro-Oeste brasileiro: a análise espacial do Sítio Guará 1 (GO-NI-100), Goiás. Revista do Museu de Arqueologia e Etnologia 6: 47-81. 


\section{Fontes documentais manuscritas}

Arquivo Público Mineiro. 1743-1749. APM-SC - 84, fl. 75: registros de cartas do governador ao vice-rei e mais autoridades da Capitania (1743-1749).

Seção colonial, manuscritos, documentos encadernados códice: APM-SC - 84, fl. 75. APM, Belo Horizonte.

Arquivo Histórico Ultramarino. 1742. AHU $A C L-C U, c x .2$, doc. 179: carta de d. Luis de Mascarenhas ao rei d. João V [...] - Vila Boa, 30/03/1742. Centro de Memória Digital da UnB, Brasília.

Arquivo Histórico Ultramarino. 1751. AHU ACL CU -008, cx. 6, doc. 465: carta de d. Marcos de Noronha ao rei São José [... - - Vila Boa, 24/01/1751. Centro de Memória Digital da UnB, Brasília.

\section{Fontes documentais impressas}

Arquivo Público do Estado de São Paulo. 1913. Documentos interessantes para a história e costumes de São Paulo. 3. ed. Tipografia Cardozo Filho, São Paulo, v. 3 e 22.

Barros, M. 1976. Notícia 7a Prática - Roteiro verdadeiro das Minas do Cuiabá, e de todas as suas marchas [...]. In: TAUNAY, A. (Org.). Relatos monçoneiros. 2. ed. Livrara Martins Editora, São Paulo, 141-147.

Camello, J.A.C. 1976. Notícias práticas das Minas de Cuiabá e Goiases [...] 1727. In: TAUNAY, A. (Org.). Relatos monçoneiros. 2. ed. Livraria Martins Editora, São Paulo, 114-123.

Campos, A.P. 1976. Breve notícia do gentio bárbaro que há na derrota das minas de Cuiabá [...] 1723. In: TAUNAY, A. (Org.). Relatos sertanistas. 2. ed. Livraria Martins Editora, São Paulo, 181-200. 